\title{
Effect of Different Crystallization Techniques on the Dissolution Behavior of Ketoprofen
}

\author{
Mudit Dixit ${ }^{\star}$, Parthasarathi K Kulkarni and Rudra S Vaghela \\ Department of Pharmaceutics, J.S.S College of Pharmacy, J.S.S. University, S.S. Nagar, Mysore-570015, Karnataka, India.
}

*For correspondence: Email: muditdixit911@yahoo.com; Tel: +919035508450

\begin{abstract}
Purpose: To enhance the solubility and dissolution characteristics of ketoprofen using various crystallization techniques.

Methods: Ketoprofen crystals were prepared by various crystallization technique including spherical agglomeration (SA), spray drying (SD), freeze drying (FD) and super cooling (SC). The crystallization medium used for all the techniques consisted of water and chloroform. Residual solvents in the crystals were determined and the crystals were characterized by DSC, FT-IR, XRD and SEM. Both solubility and dissolution behavior studies were carried out. The physical stability of the crystals were also evaluated after storage over a period of time.

Results: Residual IPA and chloroform in the crystals ranged from $4.10-5.70$ and $1.84-2.57$ ppm, respectively, which are well below their toxic limits. The crystals obtained exhibited lower crystallinity than the original drug. The solubility of FD crystals in water increased almost fivefold to $0.0926 \mathrm{mg} / \mathrm{ml}$ compared with that of the drug $(0.0172 \mathrm{mg} / \mathrm{ml})$, while the dissolution rates of the developed crystals were than that of the original crystals. For example, FD crystals demonstrated the highest dissolution $(99.9 \%)$ compared with original crystals (64.3\%). In the stability test, the dissolution profiles of the developed crystals remained largely unchanged over the period of the stability study.

Conclusion: The re-crystallization techniques used in this study can be applied to obtain modified ketoprofen for formulation of tablets of the drug with improved drug dissolution.
\end{abstract}

Keywords: Crystallization, Ketoprofen, Crystallinity, Dissolution, Stability.

Tropical Journal of Pharmaceutical Research is indexed by Science Citation Index (SciSearch), Scopus, International Pharmaceutical Abstract, Chemical Abstracts, Embase, Index Copernicus, EBSCO, African Index Medicus, JournalSeek, Journal Citation Reports/Science Edition, Directory of Open Access Journals (DOAJ), African Journal Online, Bioline International, Open-J-Gate and Pharmacy Abstracts

\section{INTRODUCTION}

Ketoprofen is a non-steroidal anti-inflammatory drug, scarcely soluble in water, and is widely used as analgesic as well as for the treatment of acute and long-term rheumatoid arthritis and osteoarthritis. Its short elimination half-life and adverse effects, such as gastrointestinal mucosa ulceration, restrict its oral use [1-2]. Due to the high barrier properties of skin, the need to use safe and effective enhancers for improving transdermal absorption of drugs is well recognized [3-6].

Formulation and manufacture of solid oral dosage forms, tablets in particular, have undergone rapid change over several decades. One of such changes is direct compression. Direct compression is economical, facilitates processing without the need of moisture and heat, and involves a small number of processing steps. In direct tableting, it is necessary to increase flowability and compressibility of the bulk powder in order to retain a steady supply of 
powder mixture to the die cavity and impart sufficient mechanical strength to the compacted tablets [7, 8].

In addition to increasing efficiency of the manufacturing process it is also important to increase the bioavailability of the drug by improving the solubility of the bulk drug powder. Freeze drying is one of such techniques to improve the micromeritic properties and dissolution of drugs. Currently, several solubilization techniques have been reported to enhance the solubility of poorly water soluble drugs; however, few literature are available on the enhancement of the solubility and dissolution of ketoprofen, and these include formation of inclusion complexes with cyclodextrin [9] and skimmed milk [10]. To enhance the dissolution rate and bioavailability of ketoprofen, a novel dry elixir dosage form was proposed [11]. The formation of ketoprofen solid dispersion and ketoprofen-dextran ester prodrug has also been reported to improve ketoprofen solubility and dissolution [12,13]. The mechanism of increased dissolution rate of drugs by solid dispersion crystallization technique has been attributed to a number of factors such as drug amorphization, increased drug solubility, reduction in particle size, a higher degree of surface area and porosity [14-17].

Therefore, the objective of the present study was to prepare different crystals of ketoprofen by various crystallization techniques and to evaluate to investigate their physicochemical properties.

\section{EXPERIMENTAL}

Ketoprofen was obtained as a gift from Micro Lab, Bangalore, India. All chemicals and buffers used were of analytical grade (Merck Pvt Ltd. Mumbai)

\section{Preparation of ketoprofen spherical agglomerates (SA)}

Ketoprofen $(4 \mathrm{~g})$ was dissolved in $25 \mathrm{ml}$ of isopropyl alcohol (IPA) at $45{ }^{\circ} \mathrm{C}$ until a clear solution was obtained. The drug solution was poured quickly into $60 \mathrm{ml}$ of water maintained at $20{ }^{\circ} \mathrm{C}$, under continuous stirring at $500 \mathrm{rpm}$ with a propeller. When fine crystals of ketoprofen begin to precipitate (5 - $10 \mathrm{~min}$ later), $10 \mathrm{ml}$ of chloroform (bridging liquid) was added. After 10 min of stirring, $5 \mathrm{ml}$ of chloroform was again added. The temperature was reduced to $5^{0} \mathrm{C}$, and after about $1 \mathrm{~h}$ stirring, the spherical agglomerates formed were separated from the solution by filtration, dried at $45{ }^{\circ} \mathrm{C}$ for $12 \mathrm{~h}$ and kept in a desiccator room temperature until used in further experiments.

\section{Preparation of spray-dried ketoprofen crystals (SD)}

Ketoprofen $(4 \mathrm{~g})$ was dissolved in $25 \mathrm{ml}$ of IPA at $45{ }^{\circ} \mathrm{C}$ until a clear solution was obtained. The drug solution was poured into chloroform (15 ml) at room temperature. The resulting solution was spray dried (Mini Spray Dryer LSD-48, Jay Instrument \& Systems Pvt, Ltd, Mumbai) at a feed rate of $10 \%,-65 \mathrm{MM}$ WC vacuum system, atomization pressure rate of $1 \mathrm{~kg} / \mathrm{cm}^{2}$, aspirator level of $35 \%$, inlet temperature of $85 \pm 2{ }^{\circ} \mathrm{C}$ and outlet temperature of $40 \pm 1{ }^{\circ} \mathrm{C}$. The crystals formed were separated using a cyclone separator, collected and stored in a desiccator at ambient temperature until use. In spray dried water is used as ketoprofen melting point is lower than the water.

\section{Preparation of freeze-dried ketoprofen crystals (FD)}

Ketoprofen $(4 \mathrm{~g})$ was dissolved in $25 \mathrm{ml}$ of IPA at $45^{\circ} \mathrm{C}$ until a clear solution was obtained. The drug solution was poured into a solvent system consisting of water $(60 \mathrm{ml})$ and chloroform $(15 \mathrm{ml})$ at room temperature. The resulting solution was transferred to a $100 \mathrm{ml}$ glass bottle and placed in an ultra-low temperature freezer at $-40{ }^{\circ} \mathrm{C}$ for 24 $\mathrm{h}$. The frozen sample was then placed in a lyophilizer (IISHIN Lab Co Ltd, Korea) for $72 \mathrm{~h}$ at a condenser temperature of $-40{ }^{\circ} \mathrm{C}$ and a pressure of $7 \times 10^{-2} \mathrm{mbar}$, followed by secondary drying at $25{ }^{\circ} \mathrm{C}$ for $24 \mathrm{~h}$. The resulting crystals were kept in a desiccator at room temperature pending further tests.

\section{Preparation of super-cooled ketoprofen crystals (SC)}

Super-cooled crystals of ketoprofen were prepared by melting the drug $(5 \mathrm{~g})$ at $95 \pm 5^{\circ} \mathrm{C}$ on a heating mantle. The resulting solid crystals were kept at room temperature for $5 \mathrm{~min}$, shifted to a freezer for $1 \mathrm{~h}$ and then kept in a desiccator at room temperature until further use.

\section{Preparation of recrystallized ketoprofen (RS)}

Ketoprofen $(4 \mathrm{~g})$ was dissolved in $25 \mathrm{ml}$ of IPA at $45^{\circ} \mathrm{C}$ and $15 \mathrm{ml}$ of chloroform added. The drug solution was poured quickly into $60 \mathrm{ml}$ of water at $20{ }^{\circ} \mathrm{C}$ with occasional stirring. The crystals of ketoprofen formed were collected by filtration and dried at $45^{\circ} \mathrm{C}$ for $12 \mathrm{~h}$. 
Determination of residual solvents in crystals

Gas chromatography (GC) was carried out on a computerized GC system (model 2014, Shimadzu Technologies, Japan) coupled with a split/splitless injector, operated in a split-mode and FID. Rtx-5 capillary column (cross bond $5 \%$ di-phenyl/95\%di-methyl-polysiloxane) with a length of 30 meters coil and an internal diameter of $0.25 \mathrm{~mm}$ was used for the studies.

\section{Differential scanning calorimetry (DSC)}

A DSC study was carried out to detect possible polymorphic transition during the crystallization process. DSC measurements were performed on a DSC DuPont 9900, differential scanning calorimeter with a thermal analyzer.

\section{Fourier transform infrared spectroscopy}

(FTIR)

FTIR spectral measurements were taken at ambient temperature (Shimadzu, model 8033, USA). About $2 \mathrm{mg}$ of the pure drug, as well as recrystallized crystals and spherical agglomerates were tested separately. Pure drug and all the prepared crystals In each case, the sample was dispersed in potassium bromide $(\mathrm{KBr})$ powder and compressed to pellets at a pressure of $6000 \mathrm{~kg} / \mathrm{cm}^{2}$.

\section{X-ray diffraction analysis}

X-ray powder diffraction patterns were obtained to detect possible polymorphic transitions during the crystallization process. The test was carried out using Rigaku Miniflex II x-ray diffractometer with $\mathrm{Ni}$-filtered radiation of wavelength of 1.5406 $\AA$ (Cu Target). The samples were scanned in the $2 \theta$ range of $0-50^{\circ}$. The scanning speed used for the recording was $3 \% \mathrm{~min}$ at steps of $0.02^{\circ}$.

\section{Scanning electron microscopy (SEM)}

Scanning electron microscopic (Joel-LV-5600, USA, magnification of $250 \mathrm{x}$ ) photographs were obtained to determine crystal nature and morphology.

\section{Particle size measurement}

The particle size of most of the crystal samples was determined by microscopy method using a calibrated ocular micrometer but the size of the spherical agglomerates was determined by sieving method and that of the freeze-dried crystals by a submicron particle analyzer (Zetasizer Nano ZS, Malvern Instruments, UK). Particle size distribution of crystals is reported by intensity. The measurement was performed at 25 ${ }^{0} \mathrm{C}$ and DTS software (version 4.0) was used to collect the analyzed data using "multi-narrow modes".

\section{Solubility studies}

The solubility of the ketoprofen crystals in water and phosphate buffer $(\mathrm{pH} 7.4)$ was determined by taking excess quantity of sample and adding to screw-capped $50 \mathrm{ml}$ glass vials filled with water or phosphate buffer. The vials were shaken for $24 \mathrm{~h}$ on a mechanical shaker. The solution was filtered through Whatman filter paper no.1 and the drug concentration was determined spectrophotometrically at $260 \mathrm{~nm}$.

\section{Dissolution studies}

Dissolution test on the ketoprofen samples was carried out using a USP dissolution test apparatus XXIV-Type II (Electro Lab Mumbai, India). The dissolution medium $(900 \mathrm{ml})$ consisted of phosphate buffer (pH 7.4). Dissolution sample fluid (10) $\mathrm{ml}$ was withdrawn at 10 min intervals over a period of $1 \mathrm{~h}$. The amount of dissolved drug was determined spectrophotometrically (model UV 1601A, Shimadzu, Japan) at $260 \mathrm{~nm}$.

\section{Determination of physical stability}

To determine the physical stability of SA, SD and $\mathrm{FD}$, they were placed in a climate chamber set at $40{ }^{\circ} \mathrm{C}$ and $75 \%$ relative humidity (RH). After 90 days, dissolution test was carried out on the stored samples and the data compared with those of the freshly prepared crystals.

\section{Statistical analysis}

Comparison among the prepared crystals and the reference (pure ketoprofen) were made by Student t-test at $95 \%$ level of confidence using Microsoft Office Excel 2007.

\section{RESULTS}

A typical spherical crystallization system involves a good solvent (such as IPA), a poor solvent (such as water) for a drug and a bridging liquid (such as chloroform). The selection of these solvent depends on the miscibility of the solvents and solubility of the drug in individual solvents (Fig 1).

\section{Residual solvent}

Gas chromatography (GC) results indicate that residual solvent was in the range $4.1-5.7$ and 
1.84 - $2.57 \mathrm{ppm}$ of IPA and chloroform, respectively, in the prepared crystals, was and these values are much lower than the toxic levels of 400 and $60 \mathrm{ppm}$, respectively[16,17].

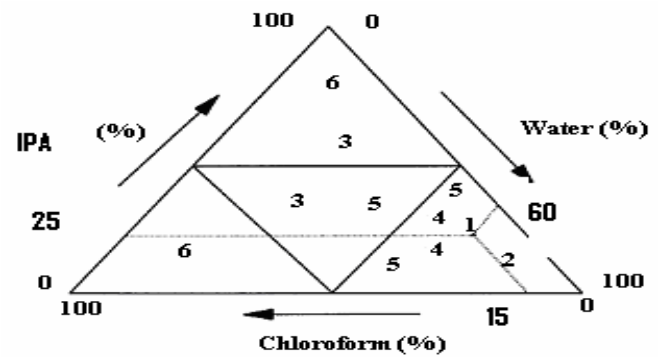

Fig 1: Ternary diagram of solvent system

\section{Thermal characteristics}

The DSC thermograms (Fig 2) show a sharp endothermic peak for all the ketoprofen crystals. This one step melt is be due to only one crystal form (triclinic) of the ketoprofen formed during the crystallization process, thus indicating that ketoprofen did not undergo any crystal modification. The temperature range of the endothermic peak for all the ketoprofen crystals 94 to $96{ }^{\circ} \mathrm{C}$. Melting points show slight variation as the nature of the crystals might have been affected by the solvent. The melting endotherm for pure ketoprofen sample was $96.58^{\circ}$ with enthalpy of $181.01 \mathrm{~J} / \mathrm{g}$ [4] whereas in the case of freeze dried crystals melting endotherm was $94.23^{\circ} \mathrm{C}$ with decreased enthalpy of $174.31 \mathrm{~J} / \mathrm{g}$, indicating decreased crystallinity.

The DSC thermogram of the super-cooled crystals (SC) of ketoprofen showed a melting endotherm at $96.23{ }^{\circ} \mathrm{C}$ with an enthalpy of $178.87 \mathrm{~J} / \mathrm{g}$, indicating decreased crystallinity but not as much as in other prepared crystals.

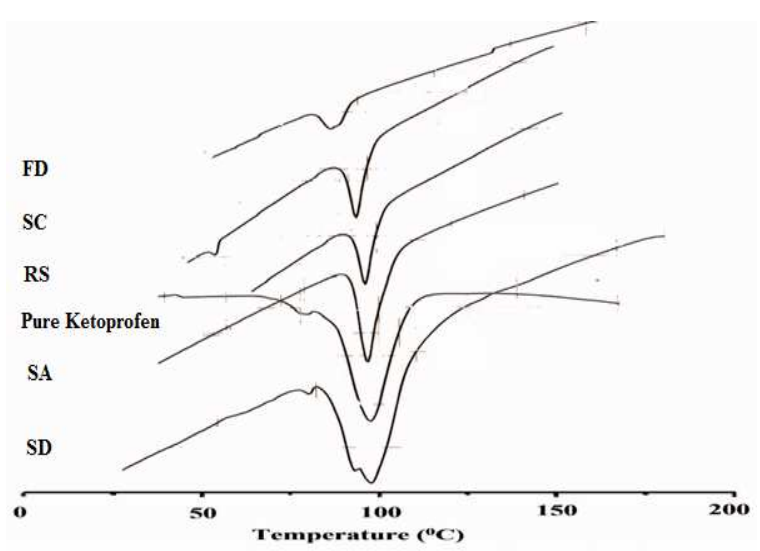

Fig 2: DSC thermograms of ketoprofen crystals

\section{Infra-red spectra}

All the prepared crystals except super-cooled crystals (SC) and original ketoprofen exhibited general characteristic peaks at $2983-2930 \mathrm{~cm}^{-1}$ (aromatic C-H stretch, carboxylic acid $\mathrm{O}-\mathrm{H}$ stretch), $1695-1649 \mathrm{~cm}^{-1}$ (C=O stretch), 1595 $\mathrm{cm}^{-1}$ (aromatic $\mathrm{C}=\mathrm{C}$ stretch), $1437 \mathrm{~cm}^{-1}(\mathrm{CH}-\mathrm{CH}$ ${ }_{3}$ deformation), $2891 \mathrm{~cm}^{-1}$ ((C-H) stretch plus O$\mathrm{H}$ deformation), $1690 \mathrm{~cm}^{-1}$ (carboxylic O-H out of plane deformation), and $860-640 \mathrm{~cm}^{-1}$ (C-H out of plane deformation for substituted aromatic) [9].

\section{X-ray diffractory}

$X$-ray diffraction was used to analyze changes in the inner structure of ketoprofen crystal during modification into the various crystals. The characteristic peak of ketoprofen appeared in the $2 \theta$ range of $0-50^{\circ}$, indicating that the original (unprocessed) ketoprofen was a crystalline material. All the samples showed similar peak positions thus ruling out the formation of polymorphs of ketoprofen. However, the relative intensities of the peaks varied according to the crystal type (Fig 3).

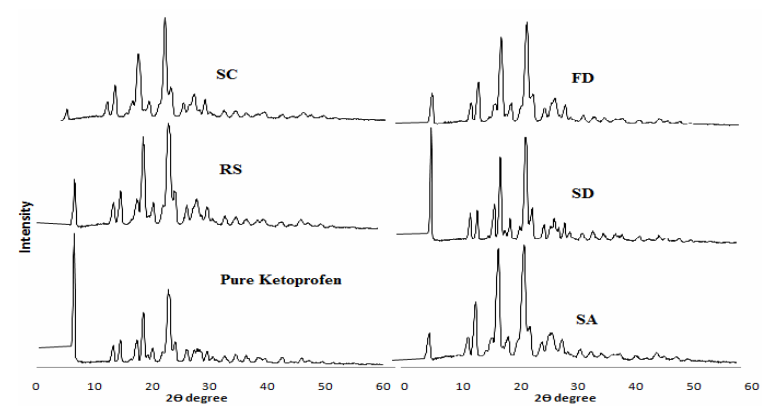

Fig 3: X-ray diffraction spectra of ketoprofen crystals

\section{Particle size and morphology}

SEM (Fig 4) show that the original ketoprofen crystals had a size range $6-17 \mu \mathrm{m}$ and were irregular in shape. Recrystallization led to crystals (RS) with intermediate size (13 $-26 \mu \mathrm{m})$ and rod-like shape. The agglomerates (SA) had a rough surface covered with numerous rodshaped crystals $(350-830 \mu \mathrm{m})$. The shape of spray-dried crystals (SC) was uniform, spherical and very small in size $(5-10 \mu \mathrm{m})$ while the freezedried crystals (FD) appeared as microcrystalline particles with a smooth surface and very small size (mean particle size, $136.8 \mathrm{~nm}$ ). Supercooled crystals (SC) had an irregular shape and rough, hard surface with yellowish color, and a size in the range $26-34 \mu \mathrm{m}$.

\section{Solubility of ketoprofen}

All the prepared crystals showed greater solubility than the original drug in water as well as in phospate buffer $(\mathrm{pH}$ 7.4). FD crystals showed the highest solubility $(0.0926 \mathrm{mg} / \mathrm{ml})$ and was 5 -fold more soluble than the original 
ketoprofen $(0.0172 \mathrm{mg} / \mathrm{ml})$ in water and nearly 4fold in phosphate buffer.

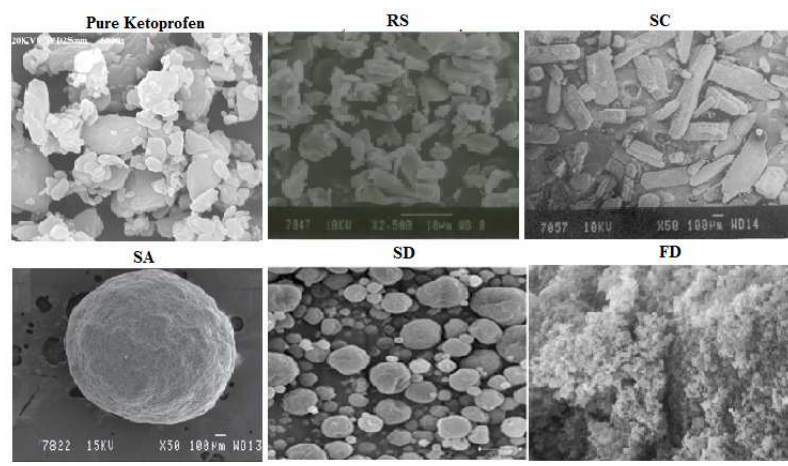

Fig 4: SEM of various ketoprofen crystals

\section{Dissolution characteristics of ketoprofen}

The dissolution profiles of ketoprofen are shown in Fig 5. The prepared crystals, except supercooled crystals, exhibited higher dissolution rate than original ketoprofen. The reason for this faster dissolution could be the better wettability of the prepared crystals and/or reduction in particle size of prepared crystals. The amount of drug dissolved in 60 min greatly varied for all the crystals.

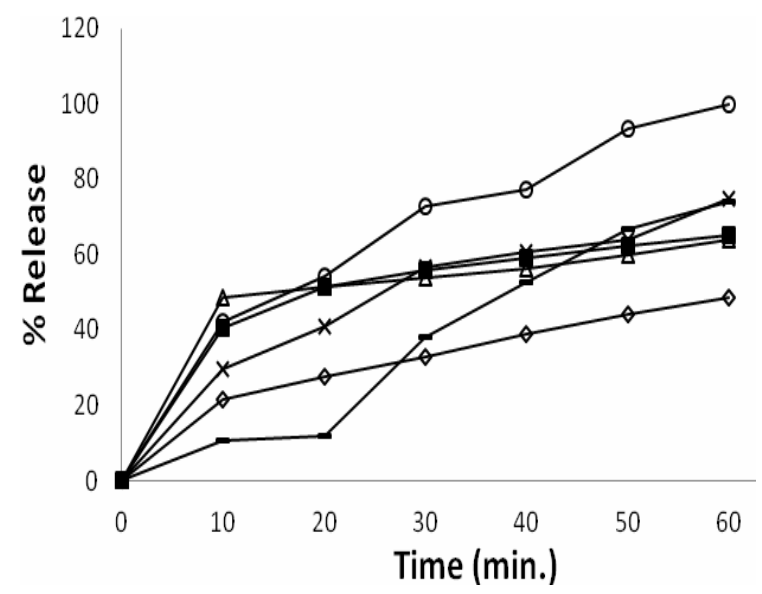

Figure 5: Dissolution of ketoprofen crystals. Key: Original ketoprofen $=\diamond, \mathrm{RS}=\mathbf{m}, \mathrm{SC}=\Delta, \mathrm{SA}$ $=x, \mathrm{SD}=-$, and $\mathrm{FD}=0$

\section{Physical stability of ketoprofen}

There was no change in ketoprofen release from the prepared crystals after 90 days of storage, when compare with the original crystals.

\section{DISCUSSION}

Isopropyl alcohol (IPA) is miscible in any proportion with water and chloroform. If the ternary diagram is drawn to select a solvent composition, chloroform/water mixture is like an emulsion in a large area of the diagram. The points on the vertex correspond to a pure liquid; those on the sides correspond to a mixture of only two liquids. Since the presence of three liquids is necessary (good solvent, bridging solvent and poor solvent) for spherical agglomeration, points on the sides of the triangle are excluded. As many as 36 points remain for experiments. Each triangle in the ternary diagram was investigated for crystallization. The optimal ratio for spherical agglomeration can be found in diagram. The proportion of IPA/water/chloroform chosen for the study was the same for all the crystallization techniques used.

Recrystallization of ketoprofen was carried to elucidate changes induced in the crystal lattice ketoprofen by the solvents used. The same solvent composition was used for all crystallization procedures[15]. Based on the high solubility of ketoprofen in IPA $(2 \mathrm{~g} / 12.5 \mathrm{ml})$, high viscosity and crystal morphology of the regenerated product, IPA is the most suitable solvent for the re-crystallization of ketoprofen. Consequently, control of residual IPA is required, being a toxic organic solvent. However, since its residual concentration in the products below the minimum levels, to the re-crystallized products should be fit for human consumption $[16,17]$.

DSC results indicate that the crystallinity decreased in all the prepared crystals except super-cooled crystals. This suggests that there was increased amorphous fraction as a result of the preparative processes. Specific changes in IR spectra are not very clear, but these could be due to variations in the resonance structure, rotation of a part of a molecule, certain bonds, minor distortion of bond angles, or even the presence of solvent of crystallization. Infrared spectra of pure Ketoprofen, RS, SA, SD, FD crystals showed characteristic peaks in same position. It would appear that the super-cooled crystals prepared by heating the drug before cooling it, has a different crystalline form from that in the original sample and in all other prepared crystals. The reduced relative intensities of all the prepared crystals, compared with the original drug can be attributed to the markedly different crystal habits of the materials. Thus, the relative abundance of the planes exposed to the x-ray source would have been altered, producing variations in the relative intensities of the peak or may be due to differences in crystal sizes [10,11]. The original drug exhibits its characteristic diffraction peaks at various diffraction angles indicating the presence of crystallinity. Changes in crystallinity may explain the observed enhancement of solubility 
and dissolution of ketoprofen from the various crystal types.

Agglomerates (SA) were formed by coalescence of the microcrystalline precipitate formed, The spherical shape of the spray-dried crystals prevented the crystals from progressing to cake formation during storage due to minimal points of contact on crystal surface, thereby increasing the stability of the preparation,

The enhanced solubility of almost all the prepared crystals may be due to their higher wettability and/or reduction in particle size. On the other hand, the increased solubility of the super-cooled crystals may be due the change in drug molecules or conversion to other molecules. The dissolution behavior of the prepared crystals remain unchanged during storage. This implies that their residual solvent and crystallinity level remained constant during the storage, thus indicating that the prepared crystals when formulated into dosage forms are likely to retain their solubility and dissolution.

\section{CONCLUSION}

Spherical agglomeration, spray drying and freeze drying techniques are suitable methods for regenerating ketoprofen, a poorly soluble drug. The regenerated crystals, being more soluble and with faster dissolution rate, would be appropriate for the formulation of ketoprofen tablets of higher bioavailability by direct compression.

\section{ACKNOWLEDGEMENT}

The authors are thankful to Micro Labs, Bangolore, India for the gift of ketoprofen and to Dr. HG Shivakumar, Principal, J.S.S.College of Pharmacy, Mysore for providing facilities to carry out this work.

\section{REFERENCES}

1. Cordero JA, Alarcon L, Escribano $F$, Obach $R$, Domenech J. Comparative study of transdermal penetration of a series of nonsteroidal antiinflammatory drugs. J. Pharm. Sci. 1997; 86 . 503-507.
2. Hadgraft J, Plessis JD, Goosen C. The selection of nonsteroidal anti-inflammatory agents for dermal delivery. Int. J. Pharm. 2000; 207: 31-37.

3. Irion $G D$, Garrison $M D$, Abraham $W$. Effect of PGML excipient mixture in a transdermal system on the in vitro transport of estradiol across the skin. Pharm. Res. 1995; 12:: 1618-1622.

4. Sinh SK, Durrani MJ, Reddy IR, Khan MA. Effect of permeation enhancers on the release of ketoprofen through transdermal drug delivery systems. Pharmazie. 1996; 53: 741-744.

5. Cho YI, Choi HK. Enhancement of percutaneous absorption of ketoprofen: effect of vehicles and adhesive matrix. Int. J. Pharm. 1998; 169: 95-104.

6. Sridevi S, Diwan PVR. Optimized transdermal delivery of ketoprofen using $\mathrm{pH}$ and hydroxypropyl_cyclodextrin as co-enhancers. Eur. J. Pharm. Biopharm. 2002; 54: 151-154.

7. Chourasia MK, Vaidya $S$, Jain $N$, Jain $S K$, Jain $S$. and Jain $A$. Utilisation of spherical crystallization for preparation of directly compressible materials. Indian Drugs 2004; 41: 319-329.

8. Kulkarni PK, Nagavi BG. Spherical crystallization: Indian J Pharm Edu 2002; 36: 66-73.

9. Lu WL, Zhang $Q$, Zhend $L$, Antipyretic, analgesic and anti-inflammatory activity of ketoprofen betacyclodextrin inclusion complexes in animals. Biol. Pharm. Bull. 2004; 27: 1515-1520.

10. Topalogu Y, Yener $G$ and Gonullu $U$. Inclusion of ketoprofen with skimmedmilk by freeze drying. II Farmaco, 1999; 54: 648-652.

11. Ahn HJ, Kim, KM, Kim CK. Enhancement of bioavalability of ketoprofen using dry elixir as a novel dosage form. Drug. Dev. Ind. Pharm, 1998; 24: 697-701.

12. Jachowicz $R$, Nurnberg $E$. Solid dispersion of ketoprofen in pellets. Int. J. Pharm. 2000; 206: 1321.

13. Solankar AK, Jagtap AG. Chronobiological and chronopharmacological studies of ketoprofen and its solid dispersion from using adjuvant arthritis model in rats. Indian. J. Exp. Biol., 2005; 43: 46-52.

14. Teófilo V, Bruno S, Paulo C. Solid dispersions as strategy to improve oral bioavailability of poor water soluble drugs, Drug Discov. Today 2007; 12: 10681075.

15. Mudit Dixit, Parthasarathi K. Kulkarni. Preparation and Characterization of Spherical Agglomerates of Piroxicam. Lat. Am. J. Pharm. 2011; 30: 13831388.

16. Amoore JE, Hautala E. Odor as an aid to chemical safety: odor thresholds compared with threshold limit values and volatilities for 214 industrial chemicals in air and water dilution. $J$ of App Tox 1983; 3: 272-290.

17. Heywood R, Sortwell RJ, Noel PRB, Street AE, Prentice DE, Roe FJC, Wadsworth PF, Worden AN. Safety evaluation of toothpaste containing chloroform. III. Long-term study in beagle dogs. J. Environ. Pathol. Toxicol. 1979; 2: 835-851. 